\title{
An Efficient Clustering for Data Aggregation with Reliable Routing in WSN
}

\author{
Sneha Kamble ${ }^{1}$, Tanuja S. Dhope ${ }^{2}$ \\ ${ }^{1}$ Savitribai Phule Pune University, GHRCEM Pune, Maharashtra, India \\ ${ }^{2}$ Savitribai Phule Pune University, GHRCEM Pune, Maharashtra, India
}

\begin{abstract}
In international packages Wireless Sensor Networks (WSNs) plays a critical pose nowadays. The value of WSNs basically depends on the statistics collection scheme. Several data collection schemes such as multipath, chain, tree, and cluster and hybrid topologies are presented in literature for congregation records in WSNs. but, the prevailing facts collection schemes fail to offer an assured reliable network in terms of mobility, traffic, and cease-to-give up connection. On this paper, a pace strength-efficient and hyperlink-aware Cluster-Tree (VELCT) scheme for records collection in WSNs is proposed which could in fact moderate the effort of insurance distance, mobility, postpone, visitors, tree depth, and quit-to-give up connection. In this paper, a speed energy-efficient and link-aware Cluster-Tree (VELCT) method for statistics collection in WSNs is proposed which might well moderate the issues of insurance distance, mobility, delay, site visitors, tree intensity, and quit-to-stop connection. The proposed VELCT constructs the data series Tree (DCT) primarily based on the cluster head vicinity. The facts collection node inside the DCT does no longer participate in sensing on this precise round, however, it genuinely collects the statistics packet from the cluster head and can provide it to the sink. The designed VELCT scheme minimizes the power exploitation, reduces the quit-to-quit put off and site visitors in cluster head in WSNs by means of effective usage of the DCT. The power of the VELCT set of rules is to assemble a simple tree structure, thereby reducing the power intake of the cluster head and avoids common cluster formation. It additionally continues the cluster for a considerable amount of time. Simulation outcomes have tested that VELCT gives better QoS in terms of energy intake, throughput, give up-to-quit put off, and community lifetime for mobility-based totally WSNs.
\end{abstract}

Keywords: Velocity energy-efficient and link-aware cluster tree, data collection tree, data collection node, cluster tree, wireless sensor networks

\section{Introduction}

WSNs have most recently come into prominence because they hold nano generation and MEMS (Micro ElectroMechanical systems) to design networks with tiny distributed sensors and actuators. Likewise, talented technology in statement hardware, low energy VLSI and embedded computing are blended collectively to make this technology seem as a reality, the blending of computing and communications (i.e., electronic era and wireless communication) makes probable to revolutionize in lots of segments of our existence. Selecting a right topology facilitates to enhance the performance, insurance, life of the community and QoS of the network. An efficient topology guarantees that associates are at a minimum distance and reduces the possibility of a packet being lost among sensor nodes. One very essential parameter that plays a main function within the performance of WSNs is electricity consumption. Strength consumption is directly related to the transmission distance between the sensor nodes.

\section{Related Work}

In this paper [1] the author observed and studied the statistics series is a essential characteristic furnished by means of wireless sensor networks. A way to efficiently acquire sensing data from all sensor nodes is critical to the overall performance of sensor networks. In this paper, we intention to understand the theoretical limits of statistics collection in a TDMA-primarily based sensor community in phrases of possible and practicable most capability. Previously, the examiner of data collection capacity has focused on largescale random networks. However, in most of the sensible sensor applications, the sensor network is not uniformly deployed and the wide variety of sensors may not be as huge as in principle. Therefore, its miles important to look at the capacity of statistics collection in an arbitrary network. In this paper, author first derives the upper and decrease bounds for statistics collection ability in arbitrary networks under protocol interference version and disk graph model. We display that an easy BFS tree primarily based approach can lead to order-greatest overall performance for any arbitrary sensor networks. We then have a look at the ability bounds of facts collection beneath a general graph model, in which two closes by nodes may be unable to speak due to barriers or direction fading, and discuss overall performance implications. Sooner or later, we provide discussions at the design of facts series underneath bodily interference version or Gaussian channel model.

In this paper, we present a circle of relatives of adaptive protocols, called SPIN (Sensor Protocols for statistics thru Negotiation), that successfully disseminates statistics amongst sensors in a strength-restricted wireless sensor network. Nodes running a SPIN communication protocol call their facts using high-level information descriptors, referred to as metadata. They use meta-statistics negotiations to get rid of the transmission of redundant records at some point of the network. In addition, SPIN nodes can base their communication choices each upon software-particular knowhow of the facts and upon expertise of the sources which can be available to them. This allows the sensors to efficaciously distribute statistics given a confined power deliver. We simulate and examine the performance of two precise SPIN protocols, evaluating them to other viable methods and a theoretically most desirable protocol. we find that the SPIN protocols can deliver $60 \%$ extra facts for a given amount of

\section{Volume 5 Issue 2, February 2016}




\section{International Journal of Science and Research (IJSR) \\ ISSN (Online): 2319-7064 \\ Index Copernicus Value (2013): 6.14 | Impact Factor (2014): 5.611}

electricity than traditional techniques. We also find that, in phrases of dissemination charge and electricity utilization, the SPIN protocols perform close to the theoretical most beneficial.

In this paper [3] the author demonstrated that Sensor networks comprising of hubs with restricted battery force and remote correspondences are conveyed to gather helpful data from the field. Get-together detected data in a vitality effective way is basic to work the sensor system for a drawn out stretch of time. In [3] an information gathering issue is characterized where, in a round of correspondence, every sensor hub has a bundle to be sent to the removed base station. On the off chance that every hub transmits its detected information straightforwardly to the base station then it will drain its power rapidly. The LEACH convention displayed in [3] is an exquisite arrangement where groups are shaped to wire information before transmitting to the base station. By randomizing the bunch heads transmitted to the base station, Drain accomplishes a component of 8 change contrasted with direct transmissions, as measured as far as when hubs kick the bucket. In this paper, we propose PEGASIS (Power-Efficient Gathering in Sensor Information Systems), a close ideal chain-based convention that is a change over Drain. In PEGASIS, every hub corresponds just with a nearby neighbor and alternates transmitting to the base station, in this way diminishing the measure of vitality spent per round. Recreation results demonstrate that PEGASIS performs superior to anything LEACH by around 100 to $300 \%$ when $1 \%, 20 \%$, half , and $100 \%$ of hubs pass on for diverse system sizes also, topologies.

In this paper [4] the author presents Remote sensor systems contain commonly thick arrangements of substantial systems of little remote able sensor gadgets. In such systems, multicast is a basic directing administration for proficient information spread required for exercises, for example, code upgrades, errand task furthermore, focused on questions. Specifically, productive multicast for sensor systems is basic because of the constrained vitality accessibility in such systems. Multicast conventions that adventure area data accessible from GPS or restriction calculations are more proficient and vigorous than other stateful conventions as they stay away from the trouble of looking after circulated state (multicast tree). Since confinement is ordinarily effectively required for detecting applications, this area data can essentially be reused for upgrading multicast execution at no additional expense. As of late, two conventions were proposed to enhance two orthogonal parts of location based multicast conventions: GMR (Sanchez et al. GMR: Geographic multicast steering for remote sensor systems. In Proceedings of the IEEE SECON, 2006) enhances the exploiting so as to send proficiency the remote multicast favourable position yet it experiences adaptability issues when managing with expansive sensor systems. Then again, HRPM (Das et al. Disseminated hashing for adaptable multicast in remote.

In this paper [5] the author studied that the midst of the developing effect of remote sensor systems (WSNs) on true applications, various plans have been proposed for gathering information on multipath directing, tree, bunching, and group tree. Viability of WSNs just relies on upon the information gathering plans. Existing techniques can't give an ensured dependable system about versatility, activity, and end-to-end association, individually. To relieve such sort of issues, a basic and powerful plan is proposed, which is named as group free information accumulation tree (CIDT). After the group head race and bunch arrangement, CIDT develops an information gathering tree (DCT) taking into account the bunch head area. In DCT, information gathering hub (DCN) does not take an interest in detecting, which is essentially gathering the information parcel from the bunch head and conveying it into sink. CIDT minimizes the vitality misuse, end-to-end defer and movement of group head because of exchange of information with DCT. CIDT gives less multifaceted nature included in making a tree structure, which keeps up the vitality utilization of group head that decreases the continuous bunch arrangement and keep up a bunch for significant measure of time. The recreation results demonstrate that CIDT gives better QoS as far as vitality utilization, throughput, end-to-end postpone, and organize lifetime for portability based WSNs.

In this paper [6] the author observer Systems administration together hundreds or a large number of shoddy micro sensor hubs permits clients to precisely screen a remote situation by keenly consolidating the information from the person hubs. These systems require hearty remote correspondence conventions that are vitality effective and give low inertness. In this paper, we create and break down low-vitality versatile bunching chain of importance (Filter), a convention structural planning for micro sensor systems that joins the thoughts of vitality productive group based directing what's more, media get to together with application-particular information total to accomplish great execution as far as framework lifetime, dormancy, what's more, application-saw quality. Filter incorporates another, conveyed group development method that empowers self-association of substantial quantities of hubs, calculations for adjusting groups furthermore, pivoting bunch head positions to uniformly circulate the vitality load among every one of the hubs, and systems to empower appropriated sign preparing to spare correspondence assets. Our outcomes demonstrate that LEACH can enhance framework lifetime by a request of greatness contrasted and broadly useful multihop approaches.

In this paper the [7] the author demonstrated that remote sensor system, information combination is viewed as a key procedure for saving sensor vitality. Occasional information examining prompts tremendous gathering of crude realities, the transmission of which would quickly exhaust the sensor power. In this paper, we have performed information total on the premise of entropy of the sensors. The entropy is processed from the proposed neighborhood and worldwide likelihood models. The models give help with separating high accuracy information from the sensor hubs. We have additionally proposed a vitality proficient system for bunching the hubs in the system. At first, sensors detecting the same class of information are set inside an unmistakable bunch. The remaining unclustered sensors gauge their uniqueness with appreciation to the bunched neighbors and eventually join the minimum different group. The general execution of our proposed strategies is assessed utilizing NS-

\section{Volume 5 Issue 2, February 2016}




\section{International Journal of Science and Research (IJSR) \\ ISSN (Online): 2319-7064}

Index Copernicus Value (2013): 6.14 | Impact Factor (2014): 5.611

2 test system as a part of terms of meeting rate, total cycles, normal parcel drops, and transmission cost and system lifetime. At last, the recreation results set up the legitimacy and proficiency of our methodology.

\begin{tabular}{|c|c|c|c|c|c|}
\hline Sr.No & Paper Name & Technique & Advantages & Disadvantages & Results \\
\hline 1 & $\begin{array}{l}\text { Capacity of Data Collection in } \\
\text { Arbitrary Wireless Sensor } \\
\text { Networks }\end{array}$ & $\begin{array}{l}\text { BFS tree based } \\
\text { method, physical } \\
\text { interference model } \\
\text { or Gaussian } \\
\text { channel model }\end{array}$ & $\begin{array}{l}\text { Provide practical } \\
\text { and efficient data } \\
\text { collection methods }\end{array}$ & $\begin{array}{l}\text { Critical performance } \\
\text { of nodes, huge no. of } \\
\text { sensors }\end{array}$ & $\begin{array}{l}\text { the capacity of data } \\
\text { collection is in the } \\
\text { same order as the one } \\
\text { under protocol } \\
\text { interference mode }\end{array}$ \\
\hline 2 & $\begin{array}{l}\text { Adaptive Protocols for } \\
\text { Information Dissemination in } \\
\text { Wireless Sensor Networks }\end{array}$ & $\begin{array}{l}\text { SPIN protocols } \\
\text { and optimal } \\
\text { protocol }\end{array}$ & $\begin{array}{l}\text { easily accessible } \\
\text { and high-quality } \\
\text { information }\end{array}$ & $\begin{array}{l}\text { Missing data ,loss of } \\
\text { crucial information }\end{array}$ & $\begin{array}{l}\text { SPIN protocols can } \\
\text { deliver } 60 \% \text { more data } \\
\text { for a given amount of } \\
\text { energy than } \\
\text { conventional } \\
\text { approaches }\end{array}$ \\
\hline 3 & $\begin{array}{l}\text { The cougar approach to in- } \\
\text { network query processing in } \\
\text { sensor networks }\end{array}$ & Cougar approach & $\begin{array}{l}\text { Communication } \\
\text { energy is saved }\end{array}$ & $\begin{array}{l}\text { User cannot change } \\
\text { the behaviour, } \\
\text { battery power is } \\
\text { major decision factor }\end{array}$ & $\begin{array}{l}\text { Query optimizer } \\
\text { generates an efficient } \\
\text { query plan in network }\end{array}$ \\
\hline 4 & $\begin{array}{l}\text { PEGASIS: Power-efficient } \\
\text { gathering in sensor information } \\
\text { systems }\end{array}$ & LEACH Protocol & $\begin{array}{l}\text { reduces the amount } \\
\text { of energy }\end{array}$ & Nodes consists & $\begin{array}{l}\text { PEGASIS performs } \\
\text { better than LEACH by } \\
\text { about } 100 \text { to } 300 \% \\
\text { when } 1 \%, 20 \%, 50 \% \text {, } \\
\text { and } 100 \% \text { of nodes } \\
\text { die for different } \\
\text { network sizes and } \\
\text { topologies. }\end{array}$ \\
\hline 5 & $\begin{array}{l}\text { The ACQUIRE mechanism for } \\
\text { efficient querying in sensor } \\
\text { networks }\end{array}$ & $\begin{array}{l}\text { Flooding based } \\
\text { query and ERS- } \\
\text { expanding ring } \\
\text { search }\end{array}$ & $\begin{array}{l}\text { To obtain } \\
\text { information in } \\
\text { sensor networks }\end{array}$ & $\begin{array}{l}\text { Critical Parameters, } \\
\text { not feasible to } \\
\text { collect all } \\
\text { measurements from } \\
\text { each device }\end{array}$ & $\begin{array}{l}\text { Acquire obtains order } \\
\text { of magnitude } \\
\text { reduction over FBQ } \\
\text { and potential over } \\
60 \% \text { of reduction }\end{array}$ \\
\hline 6 & $\begin{array}{l}\text { EECS: An energy efficient } \\
\text { clustering scheme in wireless } \\
\text { sensor networks }\end{array}$ & $\begin{array}{l}\text { LEACH and } \\
\text { PEGASIS }\end{array}$ & $\begin{array}{l}\text { EECS autonomous, } \\
\text { more energy } \\
\text { efficient, good } \\
\text { distribution of } \\
\text { cluster Heads, less } \\
\text { data redundancy }\end{array}$ & $\begin{array}{l}\text { Data Gathering is } \\
\text { critical issue }\end{array}$ & $\begin{array}{l}\text { prolongs the network } \\
\text { lifetime much more } \\
\text { significantly than the } \\
\text { other clustering } \\
\text { protocols }\end{array}$ \\
\hline
\end{tabular}

[8] In this paper the author studied that Progressive directing in remote sensor systems (WSNs) is a vital subject that has been drawing in the examination group in the most recent decade. Run of the mill various leveled steering is called grouping directing, in which the system is isolated into various groups. As of late, a few sorts of atypical various leveled steering emerge, including chain-based, tree-based, matrix based steering, and zone based directing. There are a few overview papers that present and think about the various leveled directing conventions from different points of view, yet an overview on atypical progressive directing is as yet missing. This paper makes a first endeavor to give a far reaching survey on atypical various leveled steering. We offer an order of atypical various leveled steering of WSNs, and give nitty gritty examination of distinctive intelligent topologies. The most illustrative atypical progressive directing conventions are depicted, talked about, and subjectively looked at. Specifically, the preferences and inconveniences of distinctive atypical progressive directing conventions are broke down with deference to their critical exhibitions and application situations. At long last, we set forward some open issues concerning the configuration of progressive WSNs.
This overview plans to give helpful direction for framework fashioners on the best way to assess and select proper legitimate topologies and various leveled directing conventions for particular applications.

\section{Architectural View}

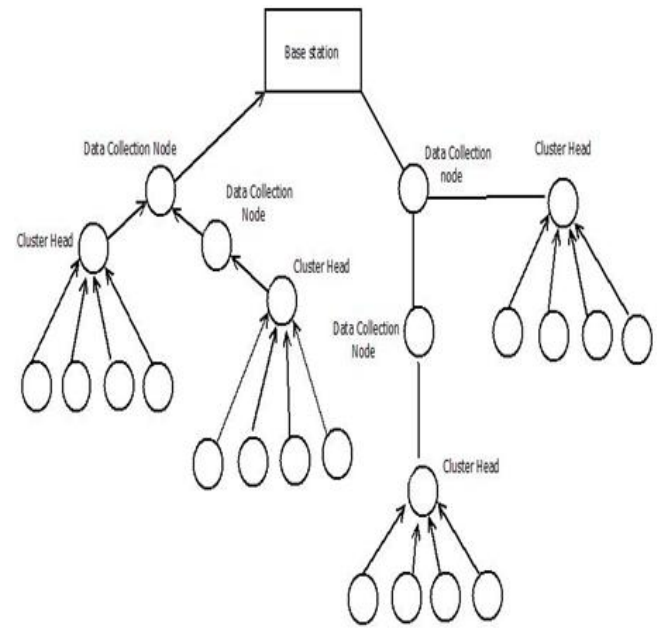

Figure 1: System Architecture 


\section{Conclusion}

On considering the raising the effect of WSNs on real time common and military applications, more number of sensor hubs are required to screen the substantial scale zones. In this paper, VELCT (Velocity Energy-productive and Linkmindful Bunch Tree) is a capable system is proposed to develop a versatility based promising system administration structural engineering for WSNs, to abuse the system lifetime, association time, leftover vitality, RSSI, throughput, PDR and stable connection for versatile sensor hubs, though every bunch part picks the bunch head with better association time and advances the information parcels to the comparing bunch head in an allotted time opening. So also, the sink or DCN chooses the one-jump neighbour DCN or bunch head with most extreme edge esteem, association time, RSSI and with less system activity. From the re-enactment results, it is uncovered that VELCT gives more stable connections, better throughput, vitality use and PDR with diminished system movement than existing conventions, for example, EEDCPTB, CREEC, CTDGA, MBC and CIDT.

\section{References}

[1] S. Chen, S. Tang, M. Huang, and Y. Wang, "Capacity of data collection in arbitrary wireless sensor networks," IEEE Trans. Parallel Diatribe. Syst., vol. 23, no. 1, pp. 52-60, Jan. 2012.

[2] J. Kulik, W. R. Heinzelman, and H. Balakrishnan, "Adaptive protocols for information dissemination in wireless sensor networks," in Proc. 5th Annu. ACM/IEEE Int. Conf. Mobile Comput. Netw. (MobiCom), Seattle, WA, USA, Aug. 1999, pp. 174185.

[3] S. Lindsey and C. S. Raghavendra, "PEGASIS: Powerefficient gathering in sensor information systems," in Proc. IEEE Aerosp. Conf., vol. 3. Big Sky, MT, USA, Mar. 2002, pp. 3-1125-3-1130.

[4] D. Koutsonikolas, S. M. Das, Y. Charlie Hu, and I. Stojmenovic, "Hierarchical geographic multicast routing for wireless sensor networks, "Wireless Netw., vol. 16, no. 2, pp. 449-466, 2010

[5] Y.-X. Jin, F.-Z. Chen, G.-F. Che, and W. Hu, "Energyefficient data collection protocol for wireless sensor network based on tree," in Proc.Asia-Pacific Conf. Wearable Comput. Syst. (APWCS), Shenzhen, China, 2010, pp. 82-85.

[6] W. B. Heinzelman, A. P. Chandrasekasan, and H. Balakrishnan, "An application-specific protocol architecture for wireless microsensor networks," IEEE Trans. Wireless Commun., vol. 1, no. 4, pp. 660-670, Oct. 2002.

[7] Z. Zhang and F. Yu, "Performance analysis of clusterbased and tree based routing protocols for wireless sensor networks," in Proc. Int. Conf. Commun. Mobile Comput. (CMC), vol. 1, Shenzhen, China, Apr. 2010,pp. 418-422 